\title{
The Pursuit of Simplified English to Support Foreign Residents in Multilingual Japan
}

\author{
Sanae Saito \\ School of English Literature, Tokai University, Kanagawa, Japan
}

Copyright $(\mathrm{C} 2018$ by authors, all rights reserved. Authors agree that this article remains permanently open access under the terms of the Creative Commons Attribution License 4.0 International License

\begin{abstract}
Japan is a country with over two million officially registered foreigners (Ministry of Justice, 2017) [1], and this number will keep rising, and it could even rise to ten million in the future. The country of Japan has a blossoming multilingual society, where various languages are heard and spoken. Actually, the government settled on a stratagem to promote tabunka kyosei, "many cultures living together" aiming for a multicultural society in 2009. The mystique of Japanese homogeneity, however, is still identifiable. Kado (2016) [2] stresses that linguistic and social isolation that foreign residents experience should be attributable to Japanese "insularity". Furthermore, Kawahara (2007) [3] maintains that language support is essential in multicultural societies to make their lives more sound. This paper attempts to examine possibilities of simplified English to help foreign residents participate in society fully based on the findings of actual conditions of language-support services for them. Interviews with foreign residents living in a middle-sized city were conducted and the comprehensibility of public information in English provided by the local government was examined. The results indicate that most of the respondents show that although the recent automatic translation systems have made public services obtainable in different languages including English, they still experience disadvantages in communicating with Japanese people. The foremost linguistic and cultural barriers they often face include, (1) isolation from the mainstream community; (2) difficulty in understanding Japanese social systems, and (3) educational disadvantages for children such as difficulties in improving academic language skills, loss of their mother language and ethnic discrimination. In order to facilitate language support that meets the needs of foreign residents to help them participate actively in society, the results of the present study suggest that simplified English in support of foreign residents can be enhanced in multilingual Japan.
\end{abstract}

Keywords Language Support, Homogeneity, Multilingual Japan, Simplified English, Tabunka Kyosei

\section{Introduction}

Japan's population began to decline in 2005 and the country is facing a full-scale depopulating society now. According to the Statistics Bureau at the Ministry of Internal Affairs and Communications; hereafter MIAC (2016) [4], Japan is a country of roughly 127.1 million people and this number is expected to drop to nearly 90 million by the year 2050. Meanwhile, the number of foreign residents in Japan, which was 1.92 million in 2003, has been rising every year, and reached 2,471,458 in 2017 , constituting nearly two percent of Japan's overall population (Ministry of Justice, March, 2017) [1]. This was a 5.2 percent increase from the previous year and the largest number since 1959. The Chinese are the largest in number $(695,522$ people), followed by Koreans $(453,096)$, Filipinos $(243,662)$, Vietnamese $(199,990)$ and Brazilians $(180,923)$. Particularly, the number of Asians such as Vietnamese has been growing. These demographic changes have had quite a dramatic impact on Japan, stressing issues which had been hidden by Japan's representation as a homogeneous nation even if the percentage of foreign residents is smaller than in some other industrialized countries (Lie, 2001 [5]; Oguma, 1995 [6]; Weiner, 1997, [7]).

Regarding the belief in Japanese homogeneity, some researchers consider the mystique of Japanese homogeneity from distinctive angles. Having historically seen Japan as homogeneous, monolingual and mono-ethnic (Maher, 1995) [8], Japan is now faced with pressing questions about how to deal with the increase in migrants. Ogata (2015) a political scientist, for instance, [9] fears that Japanese people tend to reject those from other countries more than ever, especially when it comes to the immigration issues. Nakane (1978) [10] maintains that Japanese people are always conscious of maintaining "inside-outside" distinctions and harmony in a group to maintain. In this light, it is undeniable that some Japanese may be opposed to the idea of a multicultural society accompanying a steady increase of foreign residents living and working in Japan. They might believe that a multilingual society could lead to the breakup of the nation. 
Furthermore, other Japanese researchers pay attention to the issue of social exclusion from the view of common problems non-Japanese residents face such as their children's experience of "invisibility" at school (Ota, 2000 [11]; Shimizu and Shimizu, 2001 [12]). They often experience social isolation because the nature of the Japanese education system is nationalistic and thus there are arguments for educational reform to accept children with different cultural backgrounds (Ota, 2000 [11]); Yoon, 1996 [13] and 1997 [14]). Consequently, people of the same nationality may gather together and establish their own "island-within-an-island" communities. It may be easier that way, and more convenient as no language and cultural barriers exist in a segregated society.

Considering the recent pluralizing communities seen in Japan, Noyama (2007) [15] emphasizes that the necessity of language support is growing as Japan is rapidly shifting into a multilingual and multicultural society due to an influx of people from overseas. Furthermore, Kado (2016) [2] points out that the public awareness of tabunka kyosei, should be enhanced in a multilingual and multicultural society. One example of tabunka kyosei emerged following the great Hanshin-Awaji earthquake of 1995 when Japanese and other non-Japanese residents living in the same devastated neighborhoods began to help each other. Accordingly, the necessity of simplified languages to support for non-Japanese residents has been expected all the more since then (Kawahara, 2007 [3]; Noyama. 2007 [15]).

In fact, some local governments with a heavy concentration of foreign residents such as Osaka in the western part of Japan have taken the initiative to endeavor to enhance language support for them based on empirical data gained through a survey to reveal what is needed with respect to language (Yao, 2009) [16]. Although their measures are still in planning, some services are being put into action through helping foreign children with language learning as well as their homework in Japanese, or setting up a consulting services for those who in need in their mother languages. Nonetheless, researches and practices of language support, in particular, providing public information in one common language, currently English as a multicultural language, to share with many citizens are still insufficient.

This study attempts to consider possibilities of simplified English in support of non-Japanese residents based on their need for language support. Ultimately, this study explores roles of language support for non-Japanese residents to help them maintain their linguistic and ethnic identities in contemporary pluralizing society in Japan.

\section{Literature Review}

\subsection{Multilingual Japan in the Demographic Context}

As seen above, the social and economic effects of such noticeable changes in its population must have made many citizens concerned about the future of the nation. In response to the decline of its population, the government has recently proposed to the greatly increase the number of foreigners living and working. That is, it seems that Japan needs a steady increase of foreign workers such as caregivers and skilled workers for manufacturing industries to maintain its economy and national population, and will not be able to do so without immigrants. In the age of changing demographics, the characteristics of Japan or Japaneseness and the country will undergo further transformation.

Accordingly, national ethnic distinctions may less become deterministic as the country experiences more exchanges and encounters with various people from different countries would take place not only in big cities with a heavy concentration of foreign residents but also in local areas. Such a social transformation could lead to multilingual and multi-ethnic, or new pluralized communities in Japan that are apt to integrate diversity.

\subsection{English as a Multicultural Language}

As has been mentioned earlier, English is generally viewed as an international language that is shared by many people in various countries. If English is accepted as a lingua franca for many people in the world (Harmer, 2001:1) [17], then there would be more chances to interact in English with non-native speakers than with native speakers of English. Japanese people thus could be more likely to use English with Chinese, Koreans or Filipinos. The issues of English proficiency would become more complex. It is assumed that diverse varieties of English would be acknowledged to facilitate communication in a context where a constant migration between a wide variety of non-native English and communities exists.

Countries including Japan in the world are thus becoming more multilingual and multicultural with a constant flow of people of various nationalities. These people with different cultural backgrounds may bring different varieties of English. That is, a language with a variety of characteristic may emerge from various cultures. Cheshire, 1991 [18]; Swan \& Smith, 2001 [19] claim that English as an international language should pay more attention to the variety of Englishes since each of these varieties has unique linguistic characteristics such as grammar, pronunciation and vocabulary. In this respect, Smith (1983) [20] points out a concept of English as an international language as follows:

When any language becomes international in character, it cannot be bound to say one culture. A Thai doesn't need to sound like an American in order to use English well with a Filipino at an ASEAN meeting. A Japanese doesn't need an appreciation of a British lifestyles in order to use English in his business dealings with a Malaysian... (English) is the 
means of expression of the speaker's culture, not an imitation of expression of the speaker's culture, not an imitation of the culture, not an imitation of the culture of Great Britain, the United States or any other native English speaking country. (pp. 7-8)

In response to the linguistic reality mentioned above, it can be helpful to provide people of various nationalities with opportunities to use a rich variety of English. Considering the linguistic and cultural trends which have recently been observed worldwide, perhaps Japan's immediate concern should be on what measures could be taken to grasp the situations for language support for non-Japanese residents living in pluralizing communities in Japan instead of adhering to the mystique of a homogeneous society with an "island-country-mentality".

\subsection{The Need for Language Support}

While some foreign residents will have been born and brought up in Japan, many will speak little or no Japanese, let alone be able to read documents written in the Japanese writing system. As a result, they may have difficulty in communicating with people in the wider society, and they may be unable to receive the information necessary for daily life in spite of the rapid advancement of information technology. What they may need is language support.

On a technical note, Kawahara (2007) [3] defines it as support given to non-Japanese residents to help them participate more actively in Japanese society by providing them with the information they need using a language that they can understand (Kawahara, 2007:11). He (2007) [3] claims that immigrants to Japan should be able to maintain their own language, culture, and identity. With regard to a question of which language is more helpful for language support, the following three language selections can be given; (1) their mother language, (2) simplified Japanese, and (3) simplified English (Kawahara, 2007: 13) [3]. Ideally, it should be the most reasonable way to offer assistance in their mother tongues or their first language, but the use of their mother language for support could be impractical due to financial reasons and limited manpower. The second option, simplified Japanese, could potentially be within budget. As for simplified Japanese, it could be futile. On the flip side of the coin, substantial language barriers for those who have difficulty in understanding Japanese could come up. English would then be practical to use as the language is regarded as a lingua franca (Harmer, 2001:1) [17] and even non-English speakers are likely to be familiar with basic English words.

Concerning grappling with language-support problems, on one hand, one city called Yao (2009) [16] mentioned earlier examined how a comprehensive language-support services should function. Yao is a middle sized city with a heavy concentration of foreign residents located in the suburbs of Osaka, Japan and has gradually become conscious of the plight of its non-Japanese residents, who face numerous inconveniences mainly due to their insufficient knowledge of Japanese. It is reported that the city authorities started a project to enhance language-support services for these residents including publishing a bimonthly multilingual newsletter provided by the local government so that foreign residents can get necessary information in a familiar writing system (Yao, 2009) [16]. They also set up a consulting service and recruited staff members from among foreign residents who volunteered so that people could talk with compatriots and let off stream. A list of interpreters has been created to help those who need help to solve problems.

In addition, it is noteworthy that the initiative has encouragingly been further expanded with a pamphlet and a guidebook uploaded onto the official MEXT (Ministry of Education, Culture, Sports, Science and Technology; hereafter MEXT) website (MEXT, 2005 [21] and 2011 [22]). It is reported that foreign families could feel included as the public documents are translated into seven different foreign languages in order to offer a general view of Japanese schooling, procedures for starting school, matters of school life and education counseling (MEXT, 2011) [22]. Public schools today seem to open their doors to foreign children more than ever before. Nonetheless, whether they are ready to receive non-Japanese children is a different matter.

These measures shown by Yao and MEXT have already been put into action. Their efforts will surely bear fruit in the future, helping foreign residents to lead much less stressful lives. Since most of them in Japan may face common problems in Japan, further enhancement of language support for foreign residents should be urgently expanded.

\subsection{Simplified English}

As seen above, Japan is steadily becoming a multilingual society due to an influx of people from overseas. Most of the newly arrived foreign people have an insufficient knowledge of Japanese, which could cause them many problems. Adding support in an alternative language which can be easy to understand even in a case of emergency such as earthquakes and volcanic eruptions is suggested. It is assumed that simplified English for language support could help non-Japanese residents including the increasing number of non-native English speakers.

For one thing, Chen (2015) [23] investigates simplified technical English for writing technical manuals so that they could be understood by an international audience. Chen (2015) [23] defines that simplified English is altered or controlled to make technical documents easier to understand for both native and non-native speakers of English, and it uses a limited vocabulary and a set of writing rules, for instance, "about" is used for "concerned with". 
Chen (2015) examined [23] how simplified technical English could be used effectively in practice by showing such examples as "turn off the engines that are not required.", "please check to make sure that the engines not required are set to OFF position." or "verify that the engines that you do not require are off." These examples can be simplified as "stop the engines that are not necessary." or "stop the engines that you do not use." (Chen, 2015) [23] Words or phrases such as not required, make sure and verify in English seem to be technical or refined so that readers would have difficulty in understanding what they mean.

On the other hand, studies on artificial simplified English have been reported from the view of varieties of English. Yoneoka (2005) [24] defines artificially simplified English as a language specially made for a purpose, and the language can be based on an existing natural language or can be artificial in the light of constructed languages which possibly take place of natural languages and make human communication simpler. Yoneoka (2005) [24] investigated on different types of English to make it easier to understand for ordinary communication and identified the following six types (in Table 1) from the view of varieties of English for global communication.

Table 1. Artificial Simplified English

\begin{tabular}{|c|c|c|}
\hline Variation & Targets & Number of Words \\
\hline Basic English & English learners & $850+150$ technical \\
\hline Special English & English learners & 1,500 \\
\hline Plain English & L1 speakers & Not specific \\
\hline $\begin{array}{c}\text { Simplified } \\
\text { English }\end{array}$ & Air space & 823 technical words \\
\hline Easy English & Spread of Bible & 12,00 (Level A) \\
28,00 (Level B)
\end{tabular}

(Yoneoka, 2005: 4) [24]

Based on different types of simplified English shown in Table 1, some researchers including Yoneoka (2005) [24] and Takagaki (2015) [25] suggest the following parameters for producing simplified English; (1) express in as few words as possible, (2) paraphrase in simple words, (3) use short sentences, (4) do not use more than one topic in one sentence, (5) avoid jargon, (6) avoid idioms, and (7) avoid the passive tense. Moreover, Takagaki (2015) [25] presents a more accessible piece of English by adhering to these seven elements and the use of his common sense if what may be acceptable to non-native speakers of English. This commonsense method, however, must be developed into concrete guidelines that can be applied to documents drawn up for the needs of non-Japanese residents in Japan. It would be necessary to find a way of writing simple English that is easy to understand for as many different nationalities as possible.

Then, what English words can be understood by a large number of non-native speakers of English? There is no simple answer to this question at the moment. Each of the artificially simplified English versions examined by Yoneoka (2005) [24] has an associated word list (See Table 1). There seems to be a discrepancy in the number of words allowed from 850 to 1,500 words, or more. There are various word lists for ESL (English as a second language), such as the Ogden Word List (1930) [26] which has a list of 850 words, or the Voice of America (hereafter VoA) Word List [27] which has 1,510 words to use as guidelines.

Nevertheless, it seems to be difficult to find a new title for artificial simplified English (Yoneoka, 2005:4) [24] since each has its own particular basis such as promoting Christian ideology or to simplify administrative English for native speakers. All of the seven parameters to make English clear and precise, "simplified English" would still be helpful for many people and for various purposes. Takagaki (2015) [25] stresses that these seven elements should be applied to simplified English as one of the practical approaches of language support for foreign residents.

\subsection{Research Questions}

With an aim to examine how simplified English provided by the local government in the public sphere could be practical and helpful as language support for foreign residents living in Japan to meet their needs, this study attempts to find answers to the following two questions:

(1) What problems may foreign residents living in Japan experience in their daily lives?

(2) How are English documents such as newsletters and guidebooks provided by the local government formulated in terms of the comprehensibility of English?

Simplified English is verified based on the study results aiming at the enhancement of language support for non-Japanese residents in Japan.

\section{Method and Participants}

In order to identify problems that foreign residents may face and see how helpful simplified English could be for language support, a mixed method was used. First, interviews with eleven foreign residents were conducted for detailed information between 2015 and 2016. Second, public information such as their homepage, newsletters, pamphlets and guidebooks related to daily-life and education matters in English were examined.

\subsection{Method}

Interviews were conducted in a medium-sized city in Hiroshima Prefecture, Japan between 2015 and 2016 to 
clarify problems foreign residents face in their daily lives. Two foreign city officers, one is Chinese and the other is Japanese Brazilian, voluntarily served as interpreters for confirmation in the interviews when needed. The interviews were audio recorded and transcribed with pauses, interruptions and hesitations noted but not measured, and then extracted. Data were categorized by considering the main overall common, overarching keys and then the variants. Transcripts were translated into English, with the two city officers mentioned above retaining key concepts in the original Japanese, English, Chinese or Spanish languages in order to facilitate a deeper understanding. Subsequently, data was carefully examined to validate initial assumptions and preliminary concepts that could be used to explain the information presented in the interviews. Observation notes largely helped in the process of validation. As such, both sources of information helped produce a series of major ideas and themes that were sorted into key and subsidiary codes.

In addition to this investigation, such written materials as an English newsletter for foreign residents offered by the city and a guidebook provided by another local government near the city were analyzed based on the concept of simplified English to verify how English was presented and simplified English could be practical.

\subsection{Participants}

Eleven foreign residents living in Fukuyama city cooperated in this interview. The participants were comprised of eight nationalities as Chinese, Koreans, Brazilians, Vietnamese, Americans, Canadians, British and New Zealanders. More descriptions of them are shown in Table 2 below.

Most of the participants are workers in their $40 \mathrm{~s}$ or $50 \mathrm{~s}$, and nearly a third of them have full-time permanent employment working for a manufacturing factory. Their length of living in Japan varies; some have lived just two years and others have lived for more than twenty years. The average length of their stay is ten years and five months. As for their proficiency of the Japanese language, seven participants consider their language skills limited or not enough to use proficiently. One-third indicate that they understand Japanese well enough to communicate with Japanese people, while the others describe that differences in languages and cultures in Japan as substantial barriers to overcome regardless of the period of their stay.

Table 2. Profile of Participants

\begin{tabular}{|c|c|c|}
\hline No. & Question Items & Profile (The number of the respondents) \\
\hline 1. & Gender & $\cdot$ Male (4) $\quad \cdot$ Female (7) \\
\hline 2. & Nationality & 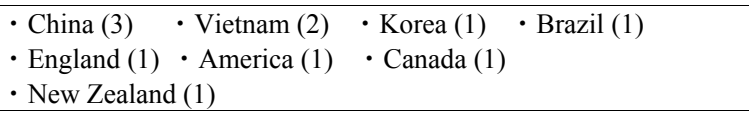 \\
\hline 3. & Mother Tongue & $\begin{array}{l}\cdot \text { Chinese (3) } \quad \cdot \text { Vietnamese (2) } \cdot \text { English (4) } \\
\cdot \text { Korean (1) } \cdot \text { Portuguese (1) } \cdot \text { Samoan (1) }\end{array}$ \\
\hline 4. & $\begin{array}{l}\text { Qualification } \\
\text { Of Stay }\end{array}$ & $\begin{array}{l}\cdot \text { Permanent resident (4) } \cdot \text { Foreign students }(3) \\
\cdot \text { International business (1) } \cdot \text { Employees (2) }{ }^{-} \text {Trainee (1) }\end{array}$ \\
\hline 5 & Length of Stay & $\begin{array}{l}\cdot 1-5 \text { yrs }(5) \cdot 6-10 \text { yrs }(0) \cdot 11-15 \text { yrs }(3) \\
\cdot 15 \text { or more than } 15 \text { yrs }(3)\end{array}$ \\
\hline 6. & Occupation & $\cdot$ Professional (3) $\cdot$ Craft (2) $\cdot$ Other (1) \\
\hline 7. & $\begin{array}{l}\text { Japanese level as the } \\
\text { participants } \\
\text { see it }\end{array}$ & $\begin{array}{l}\text { - Reading and Speaking: a little (5) } \\
\text { - Only daily conversation: very well (1) } \\
\text { - All four skills: very well (3), very limited (2) }\end{array}$ \\
\hline
\end{tabular}

Notes: Figures in parenthesis indicate the number of participants. 


\subsection{Field Site: The Regional Nature of Multilingualism}

Fukuyama is a medium-sized city with a population of roughly 470,747 located in the suburbs of Hiroshima Prefecture in the western part of Japan. According to the city statistics (November, 2017) [28], 8,613 foreign residents live there. The biggest group of people is Chinese followed by Koreans, Brazilians, Indonesians, Filipinos, and Vietnamese have steadily been increasing. In other words, nearly one in eighty residents comes from a different country. In 2009, the city [28] presented a plan called the promotion of tabunka kyosei shakai, "co-living in multicultural society" along with the government. Consequently, there are public signs written in five languages, Japanese, English, Chinese, Portuguese and Korean informing residents of the emergency evacuation areas in town. Basically, however, the city provides information for daily life in four languages, Japanese, English, Chinese, Spanish and Portuguese based on major populations of foreign residents and including Japanese. Korean and Vietnamese, inexplicably seem to be linguistically shadowed.

As for their major industries, shipbuilding, steel, textile and processing and assembly-type industries are notable. Many foreigners work at small to middle-sized related factories. In addition, the symbols of flowers and trees are the castles. All in all, the city is not known as a city which has a heavy concentration of foreign residents. In spite of the increasing number of foreign residents living there, the concept of the city's, tabunka kyosei shakai, "co-living in multicultural society" mentioned above has not yet permeated the city.

\section{Results and Discussion}

The overall findings imply that simplified English could be of help, particularly for those who speak English as a second or a foreign language with limited knowledge or skill of Japanese. As for difficulty in understanding English public materials offered by the local government including notices given by schools, most of the participants clarified that special terms, long sentences and refined expressions or so called metaphors are difficult. Their limited knowledge of grammar and vocabulary could influence their understanding of material in a written form. In terms of the proficiency of their Japanese, most of them answered that they managed to speak Japanese without any serious problems, but were not confident in reading and writing. Seven out of eleven participants were from Asian countries, and therefore, assumingly, they would use English more easily as a foreign language a little more easily than Japanese to communicate in their daily lives partly due to more complexities in learning Japanese. It is noteworthy that all of the foreign students explained that they relied upon English to communicate rather than their own homeland language or Japanese in their daily lives as well as in the academic context. Besides their language problems, the participants expressed difficulty in understanding complex social systems, and their children's school systems (see Table 3). Different social systems and cultural contexts could be some of the distinctive factors that may have created difficulties among relationships between people of two countries (Kado, 2016) [2]. The problems revealed in this survey are apparently are related with language and culture.

\subsection{Difficulties Foreign Residents Encounter}

As mentioned above, problems foreign residents face may be related to differences in language, culture and social systems. The findings show that most of the respondents express a lack of knowledge and abilities with Japanese regardless of their length of stay including educational experiences of their children, namely, foreign children's experiences in Japanese schools. It is also revealed that some even turn to English, that is, using basic English to communicate with Japanese. Table 3 indicates types of problems they are likely to encounter.

Table 3. Difficulties Foreign Residents Encounter

\begin{tabular}{|c|c|c|}
\hline Q \# & Areas & Difficulties \\
\hline 1. & $\begin{array}{l}\text { Education/ } \\
\text { Schooling }\end{array}$ & $\begin{array}{l}\text { - difficulty in helping their children learn and maintain their own homeland language } \\
\text { - } \\
\text { and culture (2) } \\
\text { children's gradual loss of mother tongue, insufficient proficiency of Japanese, and even English } \\
\text { (2) } \\
\text { difficulty in learning Japanese (4): reading and writing Chinese characters, understanding } \\
\text { katakana words, loan words } \\
\text { - } \text { difficulty in communicating with teachers and Japanese parents (3) } \\
\text { - } \text { difficulty in reading notices/contact notebooks (2) } \\
\text { - } \quad \text { difficultion about introducing their own homeland language and culture to Japanese friends } \\
\text { boxes, examinations (2) } \\
\text { bullying by Japanese classmates at school (1) }\end{array}$ \\
\hline 2. & $\begin{array}{l}\text { Medical } \\
\text { Matters }\end{array}$ & $\begin{array}{ll}\text { - } & \text { most of information about medical aid is only in Japanese (8) } \\
\text { - } & \text { difficulty in communicating with doctors and nurses (5) } \\
& \text { guide displays are only in Japanese at hospitals (3) }\end{array}$ \\
\hline 3. & Daily life & $\begin{array}{l}\text { - } \\
\text { - } \\
\text { difficulty in communicating with neighbors (3) }\end{array}$ \\
\hline
\end{tabular}

Notes: The figures in the parenthesis indicate the number of participants. 
On the whole, their concerns can be broadly classified into the following two categories. First, some problems were caused by a lack of knowledge of Japanese social systems. Another category of difficulties was related to more immediate problems they may face in their daily lives and in the education context.

One striking finding is that concerns about their children's education were the source of strain (see Q1 in Table 3). Five participants had children, and two of them found it difficult to teach their children about the language and culture of their own country of origin, and were concerned that their children were neither fluent in their own language nor Japanese. According to them, even children who are fluent in Japanese often struggle and fall behind in class due to their limited knowledge or skills in Japanese for academic purposes. Second, it could be interpreted that immigrant children gradually lose their own mother tongue when living in a foreign country even when their parents try to talk to them in their mother tongue. The process of losing one's own language is possibly explained as language attrition found in immigrants language. As Yukawa (1991) [29] maintains that one's decline in proficiency in his/her own first language could result from both isolation from other speakers of their first language and interference from the second language they are acquiring. The role of the mother tongue could not be de-emphasized much as it is deeply rooted in one's own identity. In this respect, to lose it is to lose part of themselves and their heritage (Kawahara, 2007: 13) [3].

Two of the residents stated that they had had trouble in understanding school systems such as "sweeping", namely, cleaning duties of the classroom and bringing in one's own "lunch box" (see Q1 in Table 3). On one hand, one parent noted that his child often felt isolated at lunch time bringing just a lunch box without any food contained or bringing one's own local food in a box according to their own culture. Another parent noted that her child felt offended due to the negligence of one's turn to sweep or clean as a school duty. Two parents stated that they had had difficulties in communicating with teachers and Japanese parents at schools. They further explained that they would often encounter problems in reading notices given in a contact notebook between a teacher and parents that their children brought home from school. In the end, they were unable to respond appropriately and to provide adequately for their children's school-related needs. Moreover, one Brazilian parent expressed his unease that some Brazilian children would be the target of bullying when they have an argument with Japanese classmates. According to him, remarks such as "go back to your homeland" would deeply wound the feelings and pride of the child from Brazil. Secondly, health-related concerns were also revealed (see Q2 in Table 3). It is found that eight participants had had trouble finding hospitals where doctors and staff spoke their own language, or information about medical services provided in English or their own languages. They further described that they often struggle with technical terms and many sentences in medical documents. They state that it is uneasy to communicate with doctors or nurses in even simple English. Furthermore, they explained more that signs in the hospital are largely in Japanese, which confuses them.

As for immediate trouble in their daily lives, two respondents expressed their concern that the concept of sorting out garbage into inflammable, recyclable, and kitchen garbage is different from theirs (See Q3 in Table 3). By failing to sort out their garbage properly, they explained that they had upset their neighbors. Assimilation was a key word in regard to survival and language problems could be a source of their strain due to the difficult terminology either in Japanese or English.

Finally, regarding what information the respondents would want or request the city to consider, job-related information and cultural events including sightseeing are their major concerns. Information on education is not abundant as expected. Out of the number of parents who have children, four out of eleven in this interview consider schooling to one of the major concerns of those who have children, and should be observed carefully.

Table 4. Information Needed and Requests

\begin{tabular}{|c|c|c|}
\hline Q \# & Requests & Responses \\
\hline 1. & $\begin{array}{l}\text { Necessary } \\
\text { information }\end{array}$ & $\begin{array}{ll}- & \text { Job openings (5) } \\
- & \text { Traveling or sightseeing, cultural events (5) } \\
- & \text { Medicine and health insurance (3) } \\
\text { - } & \text { Schooling (3) }\end{array}$ \\
\hline 2. & $\begin{array}{l}\text { Comments/opini } \\
\text { ons }\end{array}$ & $\begin{array}{l}\text { - More signs in English and in the katakana notation EG: City Hospital (Shimin Byoin) (5) } \\
\text { - Simpler Japanese and English: Reading and speaking Japanese are two different things. } \\
\text { Although information in English has been more available, it is still difficult to understand } \\
\text { messages mainly due to many long sentences and much use of special terminology, especially, in } \\
\text { the fields of medicine, welfare and schooling. Simpler expressions may be more helpful to } \\
\text { understand for us (7) } \\
\text { Teaching aids: EG }=>\text { tutoring to catch up with others at school in learning subjects such as } \\
\text { mathematics, social studies, science and Japanese including English for academic purposes (3) } \\
\text { Too little information for foreign students provided at school (2) }\end{array}$ \\
\hline
\end{tabular}

Notes: The figures in the parenthesis indicate the number of participants. 


\subsection{Simplified English}

The findings gained from an English guidebook are to be focused on for further discussion on simplified English. A short passage from the first page of The Globe published in May, 2010 [30] by the International Exchange Association of the city is given as an example to show the accessibility of the booklet. The table below shows these two texts. The English version of the booklet was written by a native speaker of English on a volunteer basis. The other was revised by a Japanese English teacher.

Table 5. Original Version vs. Simplified Version

\begin{tabular}{|c|c|}
\hline $\begin{array}{c}\text { English Newsletter } \\
\text { written by a Native Speaker of } \\
\text { English }\end{array}$ & $\begin{array}{c}\text { Simplified English } \\
\text { Revised by a Japanese English } \\
\text { Teacher }\end{array}$ \\
\hline $\begin{array}{l}\text { So it's that time of year } \\
\text { again-the annual Fukuyama } \\
\text { Rose Festival is upon us! This } \\
\text { month's issue of The Globe will } \\
\text { provide you with all you need to } \\
\text { know about some of the events } \\
\text { going on during the city's biggest } \\
\text { annual event, the Rose Festival, } \\
\text { on Saturday, May } 15 \text { and } \\
\text { Sunday, May 16, (p.1). }\end{array}$ & $\begin{array}{l}\text { It's that time of year again-the } \\
\text { Fukuyama Rose } \\
\text { Festival is here! This month's } \\
\text { issue of The Globe } \\
\text { will give you information about } \\
\text { some of the events } \\
\text { during the city's biggest yearly } \\
\text { event, the Rose } \\
\text { Festival on Saturday, May } 15 \text { and } \\
\text { Sunday, May 16. (p.1). }\end{array}$ \\
\hline
\end{tabular}

As seen in the simplified English version of the newsletter entitled The Globe [30], some elaborate words and common simpler vocabulary items such as "so," are deleted, expressions such as "all you need to know" are replaced by the relatively acceptable noun "information" and the verb "provide" is replaced by "give." Thus, it becomes a much more intelligible piece of English by adhering to the above guidelines, and using a linguistic sense of what may be acceptable to non-Japanese residents, in particular, non-English speaking foreign residents. The use of the common sense method, however, should be discussed and developed into concrete guidelines that could be applied to document for the needs of a large variety of non-Japanese residents. It is necessary to find other approaches to the simplification of English that can be accessible to various people including children of different countries learning English at school.

Although each of the simplified Englishes studied by Yoneoka (2005) [24] has an associated word list, there is a large discrepancy in the number of words allowed from 850 to 1,500 or more. Word lists for ESL including the Ogden Word List with 850 words [26] and VoA Word List with 1,500 words [27] may give clues on how to improve comprehensibility.

Another example of an English guidebook provided by the city for foreign residents [31] indicates the accessibility of information about preparing for disasters (in Table 6). As seen in Table 6, the words in the simplified version appear on the VoA Word List [27] whereas some essential and commonly used words, such underlined words as "earthquake" and "electricity" do not appear in the Ogden
Word List [26] which may give some clues on how to improve the comprehensibility. Furthermore, it is assumed that underlined words such as "an earthquake-prone," "refer to," "surface," "bedrock," "be aware of "routine," "appliances," "securely" and more shown in the left column in Table 6 could be considered as difficult expressions to understand.

Table 6. Original English Version vs. Simplified English Version

\begin{tabular}{|c|c|}
\hline $\begin{array}{c}\text { Original English Version } \\
\text { (written by native speakers of } \\
\text { English working for the city as a } \\
\text { translator) }\end{array}$ & $\begin{array}{l}\text { Simplified English Version } \\
\text { (revised by English speakers } \\
\text { based on the booklet in } \\
\text { simplified Japanese) }\end{array}$ \\
\hline $\begin{array}{l}\text { - Japan is an earthquake-prone } \\
\text { country. } \\
\text { - An earthquake refers to a sudden } \\
\text { shaking of the earth's surface as a } \\
\text { result of the cracking and } \\
\text { dragging of underground bedrock } \\
\text { caused by force imposed on the } \\
\text { bedrock. } \\
\text { - Be aware of the following routine } \\
\text { preparations. } \\
\text { - Make sure your furniture, shelves } \\
\text { and other large appliances stay } \\
\text { securely on the floors and to the } \\
\text { walls. } \\
\text { - What is an earthquake? } \\
\text { Whenever the boundaries in the } \\
\text { bedrock beneath our feet shift, or } \\
\text { when great pressure is exerted onto } \\
\text { the bedrock's interior and the } \\
\text { bedrock breaks, the shaking from } \\
\text { that event is transmitted to the } \\
\text { surface. When a major earthquake } \\
\text { occurs, electricity and water } \\
\text { lifelines can be cut and falling } \\
\text { buildings may cause fires or } \\
\text { other secondary damage. }\end{array}$ & $\begin{array}{l}\text {-There are many earthquakes } \\
\text { in Japan. } \\
\text { - An earthquake happens } \\
\text { when the ground moves } \\
\text { suddenly. } \\
\text { - You can prepare for } \\
\text { earthquake. } \\
\text { - Attach your furniture to } \\
\text { walls with straps so that it does } \\
\text { not fall over. } \\
\text { - Do you know about } \\
\text { earthquakes? } \\
\text { We do not know when or } \\
\text { where an earthquake will } \\
\text { happen. The ground shakes, } \\
\text { and houses and buildings are } \\
\text { destroyed. Water, electricity } \\
\text { and gas may stop. There may } \\
\text { be fires. }\end{array}$ \\
\hline
\end{tabular}

(The Guidebook for Foreigners Living Kamigyo, March, 2016) [31]

The original English in the guidebooks shown on the left in Tables 6 and 7 would expect a reader to have about 13 to 15 years of English learning, namely, one who uses English at tertiary level. The guidebook in the original English contains a seemingly higher level of words and longer sentences. As for the simplified English version, the grammar and phrases are simplified and the sentences are shorter. This is seemingly closer to the level which can be expected to be easily read by a non-native speaker of English.

As seen above, the seven elements of simplified English (Takagaki, 2015) [25] indicate that the explanation in English provided by a local government may be difficult to understand for foreign residents, particularly speakers of languages other than English. Simplified English thus could help them reduce their anxiety in a multicultural society and should be considered as an alternative communication tool for foreign residents A comprehensive language-support system with more consideration of simplified English will function. 


\section{Conclusions and Limitations}

The results of the present study indicates can be summarized by focusing on the questions mentioned earlier; (1) what problems non-Japanese residents may face in their daily lives, and (2) how public information is provided by the local government is formulated in English. The first implication drawn from this study is that social isolation from mainstream society and difficulty in understanding Japanese social systems are due to language barriers, and there may be educational inequality for children who may experience as language problems; lack of Japanese skills to catch up with others in class and children's gradual decline of their homeland language partly because children seem to value the socially dominant language over their home language. The second is that documents, newsletters and homepages provided by the government and school authorities in English are likely to be too difficult to understand for both parents and their children, filled with long sentences and technical terms.

Simplified English for support for foreign residents discussed above should be further examined carefully due to the following limitations. First, the small sample size and consequent lack of statistical power should be improved. Studies with larger numbers of non-Japanese residents need to be conducted. It would also have been more beneficial if other data sources, such as interviewing foreign children attending classes at public school, had been utilized to triangulate the data to make the results more valid. Second, it is difficult to determine the extent to which simplified English can be used by non-Japanese residents including their children who have difficulty in learning English at school. Further investigation on possibilities of simplified English is needed in educational contexts. Finally, the study should remain attentive to the development of automatic translation systems.

Notwithstanding these limitations, it is hoped that the results of this study will shed new light on the concept of simplified English in support of foreign residents living in Japan and will expand its scope and implications, and promote the enrichment of society. It is also hoped that the results will be able to enhance further exploration into language support for foreign residents in the age of tabunka kyosei, "co-living in a multicultural society". What a multicultural society needs is a constant effort to understand the differences among people, and to respect those differences.

\section{REFERENCES}

[1] Ministry of Justice. (2016). "Population of Foreign Residents in Japan". Retrieved December 15, 2016, from http://www.moj.go.jp

[2] Kado, M. (2016). Multicultural Social Work. Workshop held at Koshigaya Municipal International Center. February, 13, 2016.

[3] Kawahara, T. (2007). "Gaikokujin Jumin eno Gengo Sabisu towa" [What are Language Support Services for Non-Japanese Residents?]. In Kawahara, T. and Yoyama, H. (Eds.) Gaikokujin Jumin eno Gengo Sabisu [Language Services for Foreign Residents], (13). Tokyo: Akashi-shoten.

[4] MIAC. (2016). “Japan's population: Challenges in a society with a decreasing population. Ministry of Internal Affairs and Communications. Retrieved October 18, 2017 from http://www.soumu.go.jp/

[5] Lei, J. (2001). Multiethnic Japan. Cambridge: Harvard University Press.

[6] Oguma, E. (2002). A Genealogy of “Japanese” Self-images. Melbourne: Trans Pacific Press.

[7] Weiner, M. (ed.). (1997). Japan's Minorities: The Illusion of Homogeneity. London: Routledge.

[8] Maher, J. (1995). Multilingual Japan: An Introduction. Journal of Multilingual and Multi-cultural Development. 16 $(1,2) \cdot 1-17$.

[9] Ogata, S. (2015). "The World and Japan: Can Japan do well with the island country mentality in the age of globalization?" The Asahi, September 9, 2015. Tokyo: Asahi Shinbun

[10] Nakane, C. (1983). Japanese Society: Harmondsworth: Penguin.

[11] Ota, H. (2000). Nyukama no Kodomo to Nihongakko [Newcomers' children and Japanese school. Tokyo: Kokusaishoin.

[12] Shimizu, K. and Shimizu, M. (eds). (2001). Nyukama to Kyoiku: Gakkobunka to Esunishithi no Katto wo Megutte [The entanglement of school culture and ethnicity]. Tokyo: Akashishoten.

[13] Yoon, K. (1996). "Nation Formation and Discrimination based on Ethnicity: The Trap of Educational Research after War”. [Kokumin Keisei to Minzoku Sabetsu: Sengo Kyoiku Kenkyu no Otoshiana]. In Asahi Shinbun-sha (Ed.), Learning what education is about. [Kyoiku ga Wakaru]: 139-143. Tokyo: Asahi Shinbun-sha.

[14] Yoon, K. (1996). (1997). "The trap of 'Japanese Nation': Regarding philosophy and education after the war" ["Nihon toiu Otoshiana: Sengo Nihon no Shiso to Kyoiku ni Kanren Shite"]. In Yoon, Keun-Cha. Japanese nation: Identity of modern Japan [Nihon Kokuminron: Kindai Nihon no Aidentitti], 241- 261. Tokyo: Chikuma-Shobo.

[15] Noyama, H. (2007). Language Support Services in a City Concentrated with Foreign Residents ["Shujuchiiki no Gengo-sabisu"]. In Kawahara, T and Noyama, H. (Eds), Gaikokujin Jumin eno Gengo Sabisu [Language Services for Foreign Residents], (30-46). Tokyo: Akashi-shoten.

[16] Yao City Human-Rights Rapport Section. (2009). "A Survey Report of Investigation on Offering Information for Foreign Residents in Yao". Human Rights Section. Yao Municipal Office.

[17] Harmer, J. (2001). The Practice of English Language 
Teaching. Longman. 1.

[18] Cheshire, J. (Ed). (1991). English around the world. Cambridge: Cambridge University Press.

[19] Swan, M. \& Smith, B. (1987). Learner English: A teacher's guide to interference and other problems. Cambridge: Cambridge University Press.

[20] Smith, L. (Ed.) (1983). Readings in English as International Language. Oxford: Pergamon Press: 7-8.

[21] MEXT. (2005). Guidebook for starting school: Procedures for entering Japanese schools'. Retrieved July, 26, 2017, from

$<$ http://www.mext.go.jp/a_menu/shotou/clarinet/003/009.p df $>$

[22] MEXT. (2011). 'To children's guardians'. Retrieved July, 26,2017 , from $<$ http://www.mext.go.jp/a_menu/shotou/clarinet/003/009.p df $>$

[23] Chen, S. (2015). Simplified Technical English. ASD-STE Training Workshops. Retrieved March 28, 2018, from $<$ http://www.shufrans-techdocs.com/writing-in-simplifiedtechnical-english-at-the-c0re-of-your-documentation-strate gy/>

[24] Yoneoka, J. (2005). A Survey of Artificially Simplified Englishes: Implication for an English as an International Language. Journal of World Affairs. 33 (2): 1- 27.

[25] Takagaki, T. (2015). Acquisition and Use of English: From the Perspective of Bilingualism. Hiroshima: Keisui-sha: 126-136.

[26] Ogden, C.K. (1993). "Basic English: A General Introduction with Rues and Grammar". Retrieved July 26, 2016, from

$<$ http://www.manythings.org/vocabulary/lists/1/>

[27] Voice of America (VoA) Word List. (1997). "Special English Word List: 1510 Words". Retrieved May 5, 2016, from

$<\mathrm{http}$ :/www.manythings.org/vocabulary/lists/words.php?f $=$ voa

[28] Fukuyama City. (2009). "Fukuyama-shi Kokusai-ka Suishin Pulan." ["Fukuyama Internationalization Strategic Program"]. Retrieved May 15, 2016, from $<$ http://www.city.fukuyama.hiroshima.jp/data/fd 153jpp0p 5us71/downfile1723028511.pdf>

[29] Yukawa, E (1997). Language Attrition from the Psycholinguistic Perspective: A Literature Review. Center for Research on bililingualism. Stockholm University. Retrieved May 15, 2016, from http://paruyon.jimdo.com/guidebook

[30] The Globe (2012). Fukuyama Internationalization Strategic Plan. Retrieved May 15, 2016, from $<$ http:www.city.fukuyam.hiroshima.jp/data/fd153jppj05us 71/downfile1723028511.pdf>

[31] Kamigyo Ward Office. (2015). "Kotona in Kamigyo". Section of International at Kamigyo Ward. Kyoto, Japan. 